\title{
Depletion of Perineuronal Nets Enhances Recognition Memory and Long-Term Depression in the Perirhinal Cortex
}

\author{
Carola Romberg, ${ }^{1 \star}$ Sujeong Yang, ${ }^{2 \star}$ Riccardo Melani, ${ }^{3,4}$ Melissa R. Andrews, ${ }^{2,5}$ Alexa E. Horner, ${ }^{6}$ Maria G. Spillantini, ${ }^{2}$ \\ Timothy J. Bussey, ${ }^{6,7}$ James W. Fawcett, ${ }^{2}$ Tommaso Pizzorusso, ${ }^{3,4}$ and Lisa M. Saksida ${ }^{6,7}$ \\ ${ }^{1}$ Max Planck Institute of Psychiatry, 80804 Munich, Germany, ${ }^{2}$ Cambridge University Centre for Brain Repair, Department of Clinical Neurosciences, University of \\ Cambridge, Cambridge, CB2 0PY, United Kingdom, ${ }^{3}$ Neuroscience Institute Consiglio Nazionale delle Ricerche, Area Ricerca Consiglio Nazionale delle Ricerche, \\ Pisa 56125, Italy, ${ }^{4}$ Department of Neuroscience, Psychology, Drug Research, and Child Health NEUROFARBA, University of Florence, 50135 Florence, Italy, and \\ ${ }^{5}$ School of Medicine, University of St. Andrews, St Andrews KY16 9TF, United Kingdom, and ${ }^{6}$ Department of Psychology and 7Wellcome Trust and Medical \\ Research Council Behavioural and Clinical Neuroscience Institute, University of Cambridge, Cambridge CB2 3EB, United Kingdom
}

Perineuronal nets (PNNs) are extracellular matrix structures surrounding cortical neuronal cell bodies and proximal dendrites and are involved in the control of brain plasticity and the closure of critical periods. Expression of the link protein Crtl1/Hapln1 in neurons has recently been identified as the key event triggering the formation of PNNs. Here we show that the genetic attenuation of PNNs in adult brain Crtl1 knock-out mice enhances long-term object recognition memory and facilitates long-term depression in the perirhinal cortex, a neural correlate of object recognition memory. Identical prolongation of memory follows localized digestion of PNNs with chondroitinase $\mathrm{ABC}$, an enzyme that degrades the chondroitin sulfate proteoglycan components of PNNs. The memory-enhancing effect of chondroitinase $\mathrm{ABC}$ treatment attenuated over time, suggesting that the regeneration of PNNs gradually restored control plasticity levels. Our findings indicate that PNNs regulate both memory and experience-driven synaptic plasticity in adulthood.

\section{Introduction}

Recent studies show that specialized structures of condensed and stable extracellular matrix (ECM) known as perineuronal nets (PNNs), which form around the synapses on the cell soma and proximal dendrites of neurons (Härtig et al., 1992; Carulli et al., 2007; Carulli et al., 2010; Dityatev et al., 2010), play a key role in the control of plasticity in the CNS (Berardi et al., 2000; Kwok et al., 2011). For example, degradation of chondroitin sulfate proteoglycans (CSPGs), major components of PNNs, with chondroitinase $\mathrm{ABC}(\mathrm{chABC})$ can reopen the juvenile critical period for ocular dominance plasticity in adult rats (Pizzorusso et al., 2002). Furthermore, treatment with chABC facilitates recovery from spinal cord injury and other forms of damage to the nervous system (Kwok et al., 2011; Bartus et al., 2012). Similar results have been obtained with adult knock-out (ko) mice lacking the Crtl1/ Hapln1 gene in the CNS (Ctrl1 ko), which encodes a link protein

Received Dec. 17, 2011; revised March 14, 2013; accepted March 18, 2013.

Author contributions: C.R., M.G.S., T.J.B., J.W.F., T.P., and L.M.S. designed research; C.R., S.Y., R.M., M.R.A., A.E.H., and T.P. performed research; C.R., S.Y., R.M., and A.E.H. analyzed data; C.R., S.Y., T.J.B., J.W.F., and L.M.S. wrote the paper.

This work was supported by the Wellcome Trust, the Medical Research Council, the Alzheimer's Research Trust (United Kingdom), the National Institute for Health Research Cambridge Biomedical Research Centre, the Internationale Stiftung fur Forschung in Paraplegie, and the European Union $7^{\text {th }}$ Framework program (FP2007-2013 under grant agreements 223326, 223524, IEF 254801, the EXTRAPLAST IIT project, project Plasticise, and European Research Council project ECMneuro). J.W.F. is a paid consultant for Acorda Therapeutics, which is involved in the commercial development of chondroitinase. The other authors declare no competing financial interests.

${ }^{*}$ C.R. and S.Y. contributed equally to this study.

Correspondence should be addressed to Carola Romberg, Max Planck Institute for Psychiatry, Kraepelinstrasse 2-4,80804 Munich, Germany. E-mail: carola.romberg@gmail.com.

DOI:10.1523/JNEUROSCI.6267-11.2013

Copyright $\odot 2013$ the authors $\quad 0270-6474 / 13 / 337057-09 \$ 15.00 / 0$ essential for PNN formation, thus leading to attenuated PNNs in these animals (Czipri et al., 2003; Carulli et al., 2010).

Experience-driven changes in synaptic strength are not only a driving factor for sensory development, but are also essential for learning and memory (Bliss and Collingridge, 1993; Martin and Morris, 2002; Griffiths et al., 2008). The increase in plasticity after attenuation of PNNs in the visual cortex and elsewhere, together with the observation that chABC digestion in the amygdala enhances fear erasure (Gogolla et al., 2009), raises the intriguing possibility that a similar approach could be used to enhance the forms of plasticity thought to underlie declarative/explicit learning and memory (Squire and Zola-Morgan, 1988).

In animals, this type of memory is commonly modeled using the spontaneous object recognition task (Ennaceur and Delacour, 1988; Manns and Squire, 1999; Forwood et al., 2005; Bussey and Saksida, 2007; Eichenbaum et al., 2007; Winters et al., 2008; Saksida, 2009; Bartko et al., 2011). In the present study, we used this test, along with two methods of attenuating PNNs, to explore whether a reduction of PNNs in adult animals can enhance recognition memory. In addition, we assessed synaptic function and plasticity with extracellular field recordings in the perirhinal cortex, a structure critical for object recognition memory.

We found that either genetic reduction of PNNs in Crtll ko mice, or the less specific but more localized and reversible enzymatic degradation of PNN structures with chABC, prolonged long-term recognition memory. Furthermore, genetic or pharmacological reduction of PNNs enhanced basal synaptic transmission and long-term depression (LTD) in the perirhinal cortex, a form of synaptic plasticity thought by many to be the principal physiological mechanism underlying object recogni- 
Table 1. RM ANOVA results for Crt|1 ko mice vs Crt|1-Tg and wt mice

\begin{tabular}{|c|c|c|c|c|}
\hline Main effect or interaction & $F$ & $p$ & Simple main effects & \\
\hline \multicolumn{5}{|c|}{$\begin{array}{l}\text { Discrimination ratio with delays of } 1 \mathrm{~min}, 3 \mathrm{~h} \text {, } \\
24 \mathrm{~h}, 48 \mathrm{~h}\end{array}$} \\
\hline Genotype & $F_{(2,25)}=32.7$ & $<0.001$ & $\begin{array}{l}\text { Crt11 ko vs wt: } F_{(1,21)}=21.34, p<0.001 \\
\text { Crtt1 ko vs Crtl1-Tg: } F_{1,16}=18.2, p<0.001 \\
\text { Crtl1-Tg vs wt: } F>1, p=0.842\end{array}$ & \\
\hline Delay & $F_{(3,75)}=31.1$ & $<0.001$ & & \\
\hline \multirow[t]{2}{*}{ Genotype $X$ delay } & $F_{(6,75)}=9.2$ & $=0.003$ & Crtl1 ko vs wt & Crt11-Tg vs wt \\
\hline & & & $\begin{array}{l}1 \mathrm{~min}: F<1, p=0.121 \\
3 \mathrm{~h}: F_{(1,21)}=4.1, p=0.014 \\
24 \mathrm{h:} F_{(1,21)}=4.5, p=0.030 \\
48 \mathrm{h:} F_{(1,21)}=10.2, p<0.001\end{array}$ & $\begin{array}{l}1 \mathrm{~min}: F<1, p=0.778 \\
3 \mathrm{~h}: F<1, p=0.971 \\
24 \mathrm{~h}: F<1, p=0.882 \\
48 \mathrm{~h}: F<1, p=0.612\end{array}$ \\
\hline \multicolumn{5}{|c|}{$\begin{array}{l}\text { Discrimination ratio with delays of } \\
24 \mathrm{~h} \text { and } 48 \mathrm{~h} \text { before and after chABC treatment }\end{array}$} \\
\hline Genotype & $F_{(1,9)}=9.1$ & $=0.015$ & $\begin{array}{l}\text { Crtl1 ko vs wt } \\
\text { Before chABC: } F_{(1,9)}=18.9, p=0.009 \text {; } \\
\text { After chABC: } F<1, p=0.751\end{array}$ & \\
\hline Delay & $F<1$ & $=0.410$ & & \\
\hline $\operatorname{ch} A B C$ & $F_{(1,9)}=2.1$ & $=0.179$ & $\begin{array}{l}\text { Before vs after treatment } \\
\text { wt: } F_{(1,9)}=5.7, p=0.041 \\
\text { Crtl1 ko: } F<1, p=0.664\end{array}$ & \\
\hline $\begin{array}{l}\text { ch } A B C \times \text { genotype } \\
\text { chABC } \times \text { genotype } \times \text { delay }\end{array}$ & $\begin{array}{l}F_{(1,9)}=4.3 \\
F<1\end{array}$ & $\begin{array}{l}=0.043 \\
=0.757\end{array}$ & & \\
\hline
\end{tabular}

tion memory (Brown et al., 1987; Zhu et al., 1996; Xiang and Brown, 1998; Wan et al., 2004; Griffiths et al., 2008; Massey et al., 2008; Kealy and Commins, 2011).

\section{Materials and Methods}

Animal housing and conducting of animal experiments. All mice were housed in groups of two or three in a room with a $12 \mathrm{~h}$ light/dark cycle (lights off at 7:00 P.M.). Food and water were available ad libitum throughout the experiment. All experimentation was conducted in accordance with the United Kingdom Animals (Scientific Procedures) Act of 1986.

Genetic mouse model of PNN reduction. Postnatal neuronal expression of Crtll is the key event triggering formation of PNNs (Carulli et al., 2010). For this study, we used mice lacking the Crtl1/Hapln1 gene in the CNS, but not cartilage, which leads to attenuated PNNs in the adult cortex (Ctrl1 ko; Czipri et al., 2003). Because the Crtl1 product is essential for cartilage, Crtll was disrupted globally $\left(\mathrm{Crtll}^{-1-}\right)$, and then reintroduced under the control of the type II collagen-cartilage-specific promotor by crossbreeding with a second transgenic mouse line (Crtl1$\mathrm{Tg})$. Resulting $\mathrm{Crtll}^{-1-} / \mathrm{Crtl1}-\mathrm{Tg}$ mice were on a BALB/C background. For behavioral and electrophysiological experiments, they were backcrossed into a $129 \mathrm{sV}$ background for $>7$ generations. Testing cohorts of male, 3-month-old homozygous $\mathrm{Crtll}^{-1-} / \mathrm{Crtl1}-\mathrm{Tg}$ and wild-type (wt; $\mathrm{Crtll}^{+/+}$) littermates were obtained by pairing Crtl1 ${ }^{+/} / \mathrm{Crtl1}-\mathrm{Tg} \mathrm{fe}-$ males with $\mathrm{Crtll}^{+/-}$males. Although a cartilage-specific promoter was used to express the Crtl1-Tg, and Crtl-1 was absent from brain in Crtll- $\mathrm{Tg}$ mice (Czipri et al., 2003), we initially used a second control group of wt mice expressing the Crtl-Tg $\left(\mathrm{Crtll}^{+/+} / \mathrm{Crtl}-\mathrm{Tg}\right)$. However, no apparent behavioral differences were found between wt mice and wt mice expressing the Crtl1-Tg in cartilage (Fig. 2C,D, Table 1). Therefore, wt mice were used as the control group in all subsequent experiments. Genotypes were identified by PCR with primers for wt Crtll, disrupted Crtl1, and the Crtl1 transgene expressed in cartilage (Czipri et al., 2003).

Pharmacological mouse model of PNN reduction. PNNs have a structure similar to cartilage, in which link proteins (Crtl1/Hapln1 and Bral2/ Hapln4) stabilize the binding of various CSPGs to hyaluronan (Mörgelin et al., 1994; Watanabe et al., 1998; Carulli et al., 2007; Kwok et al., 2011). Digestion of CSPGs with the enzyme chABC leads to a marked reduction of PNNs around proximal dendrites in the cortex, although it also affects the diffuse ECM around neurons and glia (Pizzorusso et al., 2002; Gogolla et al., 2009). Protease-free chABC (Seikagaku Kogyo) or penicil-

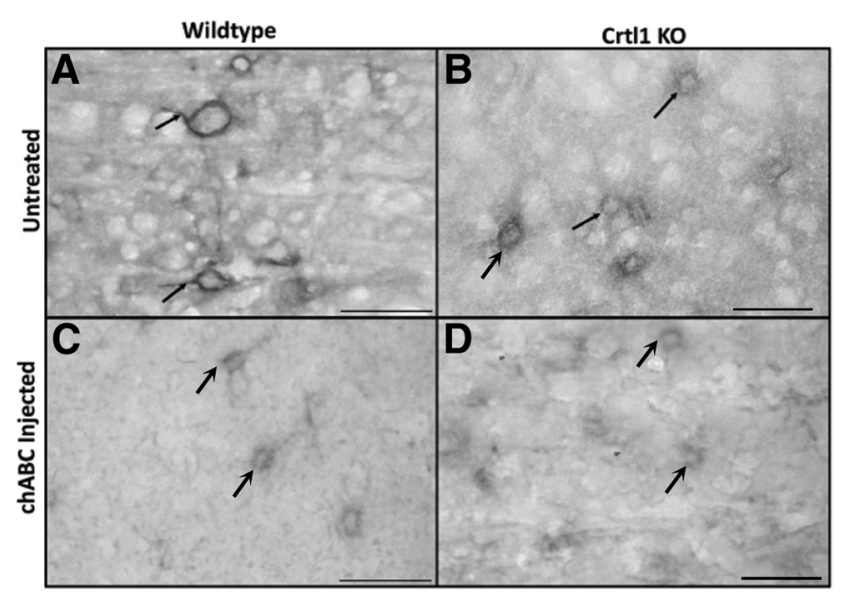

Figure 1. Depletion of brain Crtl1 and chABC injection reduce PNNs in the perirhinal cortex. $A-D$, PNNs in the perirhinal cortex in wt $(A, C)$ and $C r t 11$ ko mice $(B, D)$ before $(A, B)$ and after $(C, D) c h A B C$ injection into the perirhinal cortex. W. floribunda agglutinin labeling at high magnification indicates that PNNs are complete in wt untreated animals with PNNs covering cell bodies and dendrites ( $\boldsymbol{A}$, arrows). W. floribunda agglutinin labeling in $(\boldsymbol{C} t 11 \mathrm{ko}$ animals exhibited reduced PNNs with an absence of labeling around the dendrites ( $\boldsymbol{B}$, arrows). After chABC injection, PNNs and diffuse ECM are greatly diminished in both the wt and Crtl1 ko perirhinal cortex (C,D). Scale bar: $50 \mu \mathrm{m}$.

linase (Pnase; P0389; Sigma-Aldrich) were dissolved to $50 \mathrm{U} / \mathrm{ml}$ in $0.1 \%$ BSA and filtered through a $0.2-\mu \mathrm{m}$ filter. Six injections ( 3 per hemisphere, $0.2 \mu \mathrm{l}$ each at $0.1 \mu \mathrm{l} / \mathrm{min}$ ) were performed stereotaxically under isoflurane anesthesia with a $1 \mu \mathrm{l}$ Hamilton syringe and a 33 gauge needle at the following sites in the perirhinal cortex (in mm from bregma and the surface of the dura mater): 1 . anterior posterior (AP): -1.755 ; lateral (L): \pm 4.6; ventral (V): -4.4. 2. AP: $-2.88 ; \mathrm{L}: \pm 4.8 ; \mathrm{V}:-4.25$. 3. AP: $-3.88 ; \mathrm{L}: \pm 4.8 ; \mathrm{V}:-3.75$. After each injection, the needle was left in situ for another $4 \mathrm{~min}$ before being withdrawn. For postoperative pain management, animals received intraperitoneal injections of meloxicam (Metacam, $0.1 \mathrm{ml} / 10 \mathrm{~g}$ ).

Spontaneous object recognition. The task was conducted in a Y-shaped apparatus (Fig. 2C,D) as described previously for rats (Ennaceur and Delacour, 1988; Winters et al., 2004) and mice (Bartko et al., 2011). The 


\section{A Experimental design}

day 1-16

Object Recognition

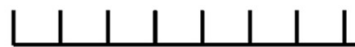

S1 S2 S3 S4 S5 S6 S7 S8

8 Sessions

( 2 for each delay: $1 \mathrm{~min}, 3 \mathrm{~h}, 24 \mathrm{~h}, 48$ h)

\section{B Object pairs}
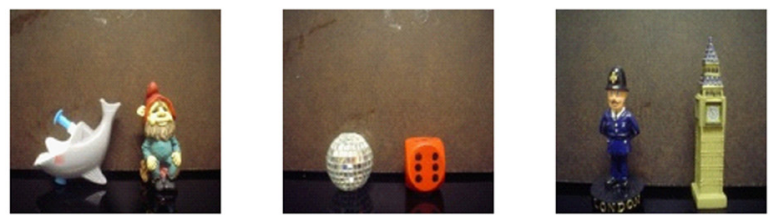
chABC injection Object Recognition

day 42

S1 S2 S3 S4

4 Sessions

( 2 for each delay: $24 \mathrm{~h}, 48 \mathrm{~h}$ )
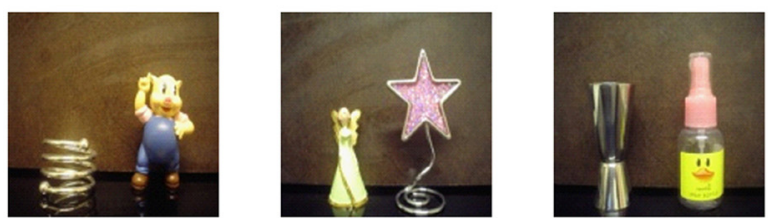

C Object recognition: sample phase

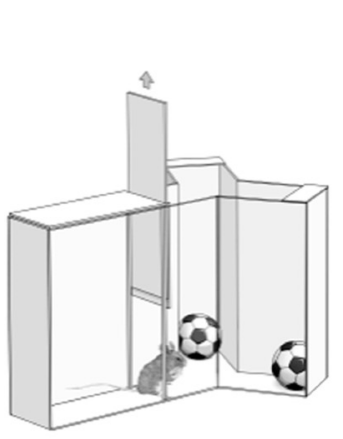

$5 \min$

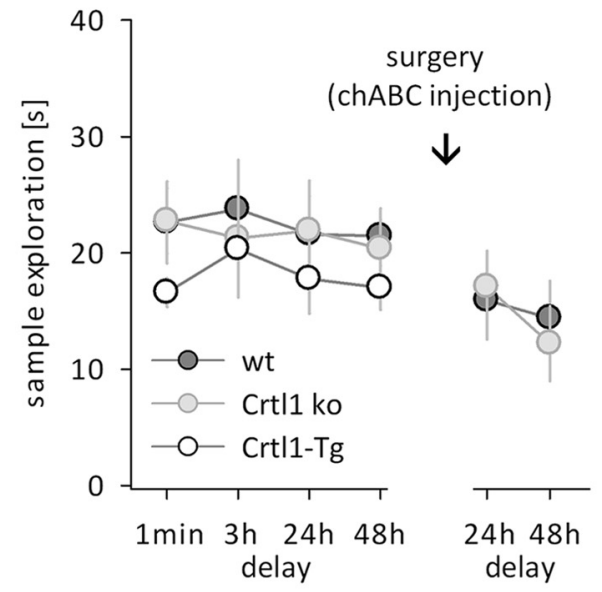

D Object recognition: choice phase
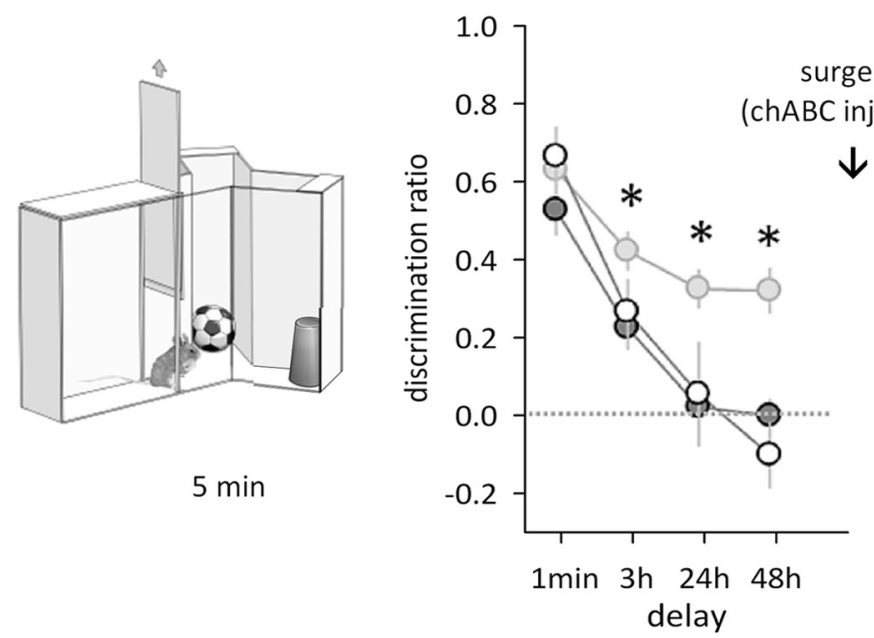

surgery

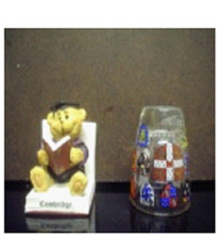

Histology

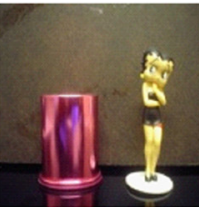

$5 \min$
Y-apparatus had high, homogenous white walls constructed from Perspex. One arm was used as the start arm and the other two arms were used to display the objects (randomly shaped junk objects, dimensions $\sim 10 \mathrm{~cm} \times 4$ $\mathrm{cm} \times 4 \mathrm{~cm}$, Fig. $2 B$ ). All walls were $30 \mathrm{~cm}$ high and each arm was $16 \mathrm{~cm}$ in length and $8 \mathrm{~cm}$ wide. A lamp illuminated the apparatus and a video camera was mounted $50 \mathrm{~cm}$ above the apparatus to record trials. All mice were habituated in two consecutive daily sessions in which they were left to explore the empty Y-apparatus for $5 \mathrm{~min}$. The following test sessions were separated by a minimum of $48 \mathrm{~h}$. Each test session consisted of a sample phase and a choice phase. In the sample phase, two identical objects A were placed at the end of each arm. The animal was left to explore the objects for $5 \mathrm{~min}$ (Fig. 2C, left panel). The choice phase followed after a delay of $1 \mathrm{~min}$, $3 \mathrm{~h}, 24 \mathrm{~h}$, or $48 \mathrm{~h}$, which the animal spent in the home cage. The choice phase was procedurally identical to the sample phase, except that one arm contained a novel object $\mathrm{B}$, whereas the other arm contained the familiar object A (Fig. $2 D$, left panel). Each animal received two test sessions for each delay. A different object pair was used for each session for a given animal, and the order of exposure to object pairs as well as the designated sample and novel objects for each pair were counterbalanced within and across groups. The time spent exploring objects was assessed from video recordings of the sample and choice phases. Exploratory bouts were scored using a personal computer running a custom made program written in Visual Basic 6.0 (Microsoft). Times where an animal climbed or sat on an object were not counted. For the choice phase, a discrimination score was calculated by dividing the difference in exploration of the novel and familiar objects by the total object exploration time. Therefore, a score of 1 corresponded to exploration of the novel object only, whereas a score of 0 corresponded to the mouse equally exploring the novel and the familiar object. The mean discrimination score across the two test sessions was calculated for each animal. Group means were compared by ANOVA with a significance level of $p<0.05$, using SPSS version 10 software.

Immunohistochemistry. Sixteen days after chABC or Pnase injections (if applicable), animals were anesthetized by intraperitoneal injections of $0.5 \mathrm{ml}$ of Euthalal (Rhône Mérieux) and perfused transcardially with $50 \mathrm{ml}$ of $0.1 \mathrm{M}$ PBS, $\mathrm{pH} 7.4$, followed by $50 \mathrm{ml}$ of $4 \%$ paraformaldehyde. The brains were removed and cryoprotected in 25\% sucrose in PBS over-

\section{$\leftarrow$}

in total). C, Sample phase. Illustration of the procedure (left) and sample exploration times before and after chABC treatment plotted separately for each delay (right). $\boldsymbol{D}$, Choice phase. Illustration of the procedure (left) and discrimination rates after each delay before and after chABC treatment (right). Data are presented as mean \pm SEM. ${ }^{*} p<0.05$, simple main effect.
Figure 2. Mice deficient in brain Crtl1 show persistent memory on an object recognition paradigm. $A$, Schematic diagram of the experimental design. $\boldsymbol{B}$, Photographs of eight representative object pairs used for object recognition experiments (of 12 pairs used 
night. Coronal sections $(20 \mu \mathrm{m})$ were cut on a cryostat. The $\mathrm{N}$-acetylgalactosamine-binding lectin Wisteria floribunda agglutinin was used to visualize PNNs. Labeling was performed by first rinsing the sections with $0.1 \mathrm{M}$ PBS, followed by quenching of endogenous peroxidase activity with $10 \%$ methanol, $2 \% \mathrm{H}_{2} \mathrm{O}_{2}$, and $0.3 \%$ Triton X-100 in PBS for $10 \mathrm{~min}$ at room temperature (RT). The tissue was rinsed in triplicate in PBS and was subsequently blocked with $3 \%$ NGS, $0.3 \%$ Triton X-100 in PBS for $1 \mathrm{~h}$ at RT. The sections were then incubated with biotinylated $W$. floribunda agglutinin $\left(20 \mu \mathrm{g} / \mathrm{ml}\right.$; Sigma-Aldrich) overnight at $4^{\circ} \mathrm{C}$. The following day, they were rinsed in triplicate in PBS and incubated with $\mathrm{ABC}$ solution (ABC Elite Kit; Vector Laboratories) for $1 \mathrm{~h}$ at RT. After the tissue was rinsed in triplicate with Tris nonsaline (TNS), it was incubated with diaminobenzidine $\left(0.5 \mathrm{mg} / \mathrm{ml}\right.$ in TNS with $0.3 \mu \mathrm{l}$ of $\mathrm{H}_{2} \mathrm{O}_{2}$; SigmaAldrich) for 5-10 min at RT. The sections were rinsed thoroughly with TNS before coverslips were applied using DPX mounting medium. Imaging was performed using a Leica DM6000 microscope for bright-field. For quantification of PNNs after Pnase or chABC treatment, 3 brain sections per animal in the range of bregma $(1.8-3.8 \mathrm{~mm})$ were photographed under $25 \times$ magnification using a digital camera attached to the microscope. All images were taken at the same settings for light and exposure. The staining intensity in the perirhinal cortex (region of interest) was analyzed using ImageJ version $1.43 \mathrm{u}$ software.

Electrophysiology. Animals were anesthetized with isoflurane and decapitated. The brain was rapidly removed and placed in ice-cold cutting solution bubbled with $95 \% \mathrm{O}_{2} / 5 \% \mathrm{CO}_{2}$ containing the following (in mm): $132.8 \mathrm{NaCl}, 3.1 \mathrm{KCl}, 1 \mathrm{CaCl}_{2}, 2 \mathrm{MgCl}_{2}, 1 \mathrm{~K}_{2} \mathrm{HPO}_{4}, 4 \mathrm{NaHCO}_{3}, 5$ D-glucose, 0.01 glycine, 1 ascorbic acid, 0.5 myoinositol, 2 pyruvate, and 10 HEPES, adjusted to $\mathrm{pH}$ 7.35. A midsagittal section was made and the rostral part of one hemisphere was cut at $45^{\circ}$ to the dorsoventral axis (Fig. $6 \mathrm{~A}$; Cho et al., 2000). The cerebellum was removed from the brain with a further caudal cut along the dorsoventral axis. The hemisphere was glued by its rostral end to a Vibratome stage (VT 1000S; Leica). Slices (350 $\mu \mathrm{m})$ of perirhinal cortex were taken in the region $-2.5 \mathrm{~mm}$ to $-4 \mathrm{~mm}$ rostral from bregma. Slices were stored submerged in bubbled, artificial CSF $\left(20-25^{\circ} \mathrm{C}\right.$, same composition as cutting solution, except $2 \mathrm{~mm} \mathrm{CaCl}_{2}, 1$ $\mathrm{mM} \mathrm{MgCl}_{2}$ ) for $2 \mathrm{~h}$ before the onset of recordings. A single slice was placed in an interface recording chamber superfused by artificial CSF $\left(30^{\circ} \mathrm{C}\right.$, flow rate $\left.2 \mathrm{ml} / \mathrm{min}\right)$. Evoked field EPSPs (fEPSP) were recorded from layers II/III from directly below the rhinal sulcus (area 35). A stimulation electrode was placed in layer II/III on the temporal side $(0.5 \mathrm{~mm}$, area 36) of the recording electrode (Fig. 6 A; Cho et al., 2000). Stimuli ( 0.1 ms duration) were delivered to the stimulation electrode at $0.1 \mathrm{~Hz}$. Input/ output curves were produced with stimulation intensities from 50 to 500 $\mu \mathrm{A}$ in steps of $50 \mu \mathrm{A}$. For monitoring baseline synaptic transmission before LTD induction, fEPSPs were reduced to $50-60 \%$ of the maximum amplitude and recorded for at least $30 \mathrm{~min}$ or until responses were stable $(<20 \%$ amplitude change over $30 \mathrm{~min}$ ). For LTD induction, $900 \mathrm{stimu}-$ lus pairs $(1 \mathrm{~ms}$ each, $20 \mathrm{~ms}$. Subsequently, fEPSPs elicited by $0.1 \mathrm{~Hz}$ stimulation were recorded for further $60 \mathrm{~min}$. Before completion of the experiment, 5 paired pulses were delivered at $0.5 \mathrm{~Hz}$, with an interval of $20 \mathrm{~ms}$. Field potentials were amplified with a CyberAmp 320 (Molecular Devices) and recorded and analyzed with custom-made software written in LabView (National Instruments). For offline LTD analysis, fEPSPs were averaged across $1 \mathrm{~min}$ and the peak amplitude of the mean fEPSP was expressed relative to the preconditioning baseline. Paired-pulse plasticity was expressed as the mean ratio of second and first fEPSP amplitude as a percentage.The significance of group means was established using either paired or unpaired $t$ tests or repeated-measures (RM) ANOVA, followed by tests of simple main effects, if applicable.

\section{Results}

Object recognition is regarded as a rodent test for declarative memory (Gaffan, 1974; Mishkin, 1978; Ennaceur and Delacour, 1988) and depends, in the present version, on the perirhinal cortex (Winters et al., 2004). We visualized PNNs in this cortical region of 4-month-old Crtll ko mice by postmortem $W$. floribunda agglutinin staining (Härtig et al., 1992). In wt mice, PNN

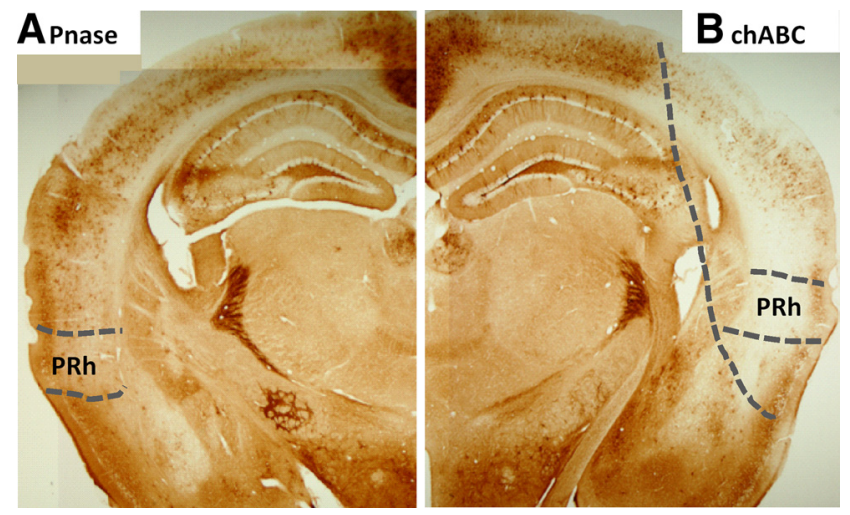

Figure 3. Effect of enzyme injection into the perirhinal cortex. $\boldsymbol{A}$, Pnase injections into the perirhinal cortex (PRh) had no effect. $\boldsymbol{B}$, chABC injections attenuated PNNs in the perirhinal cortex and adjacent cortical areas. In the right section, the area of chABC digestion and PNN depletion is indicated by the long dashed line.

structures were clearly visible both around the cell bodies and proximal dendrites (Fig. 1A). Consistent with our previous observations in other cortical regions (Carulli et al., 2010), PNNs in the perirhinal cortex of Crtll ko mice were vestigial around the somata and absent around the dendrites (Fig. 1B).

To address whether the reduction of PNNs altered recognition memory, we tested 4-month-old Crtl1 ko mice (Crtl1 ${ }^{-/-}$, Crtl1-Tg) and two litter mate control groups, wt mice overexpressing Crtl1 in cartilage (Crtl1-Tg) and wt mice (Fig. 2A, cohort 1, Crtl1 ko $n=11$; Crtl1-Tg $n=6$; wt $n=11$ ) on a spontaneous object recognition paradigm highly sensitive to perirhinal cortex lesions (Ennaceur et al., 1996; Murray and Bussey, 1999; Winters et al., 2004). A sample object was presented to the animals (Fig. 2C) and, after a delay of $1 \mathrm{~min}, 3 \mathrm{~h}, 24 \mathrm{~h}$, or $48 \mathrm{~h}$, recognition memory was tested by measuring exploration times of a novel object and the previously presented familiar object (Fig. 2D). Crtll ko mice performed differently from both control groups on the choice phase of the task, which assesses the persistence of memory for the sample object (Fig. 2D, Table 1). Although all groups showed a similar preference for the novel object when the delay between sample and choice phase was short (i.e., when the mnemonic demand was low), Crtl1 ko mice showed enhanced object recognition after longer delays (Fig. 2D, Table 1). Strikingly, Crtl1 ko mice continued to treat sample objects as familiar even after $48 \mathrm{~h}$, whereas Crtl1-Tg and wt mice showed no memory of the familiar object after $24 \mathrm{~h}$ (one-sample $t$ test comparing with chance performance (0): Crtl1 ko $24 \mathrm{~h}$ : $t_{(10)}=7.3, p=0.004,48 \mathrm{~h}: t_{(10)}=5.3, p=0.005$; Crtl1-Tg $24 \mathrm{~h}:$ $t_{(5)}=0.5 ; p=0.782 ; 48 \mathrm{~h}: t_{(5)}=0.3 ; p=0.877 ;$ wt $24 \mathrm{~h}: t_{(10)}=0.1$, $\left.p=0.921 ; 48 \mathrm{~h}: t_{(10)}=0.5, p=0.788\right)$. Because we found no differences in object recognition between the two control groups (Crtl1-Tg and wt, Fig. 2C,D, Table 1), we continued the subsequent experiments with Crtl1-ko and wt controls. Prolonged object recognition in Crtll-ko mice was not due to enhanced exploration of the sample object, because sample phase exploration times were similar in all groups (Fig. 2C, RM ANOVA, no main effect of genotype, delay or delay $\times$ genotype interaction, all $F<1$ ). However, we cannot entirely exclude the possibility that more subtle changes to anxiety levels, in particular toward novelty, contributed to the results. Nevertheless, the large memoryenhancing effect in the absence of major differences in sample exploration, and the fact that choice phase performance was similar between groups at shorter delays, suggest that such changes to 

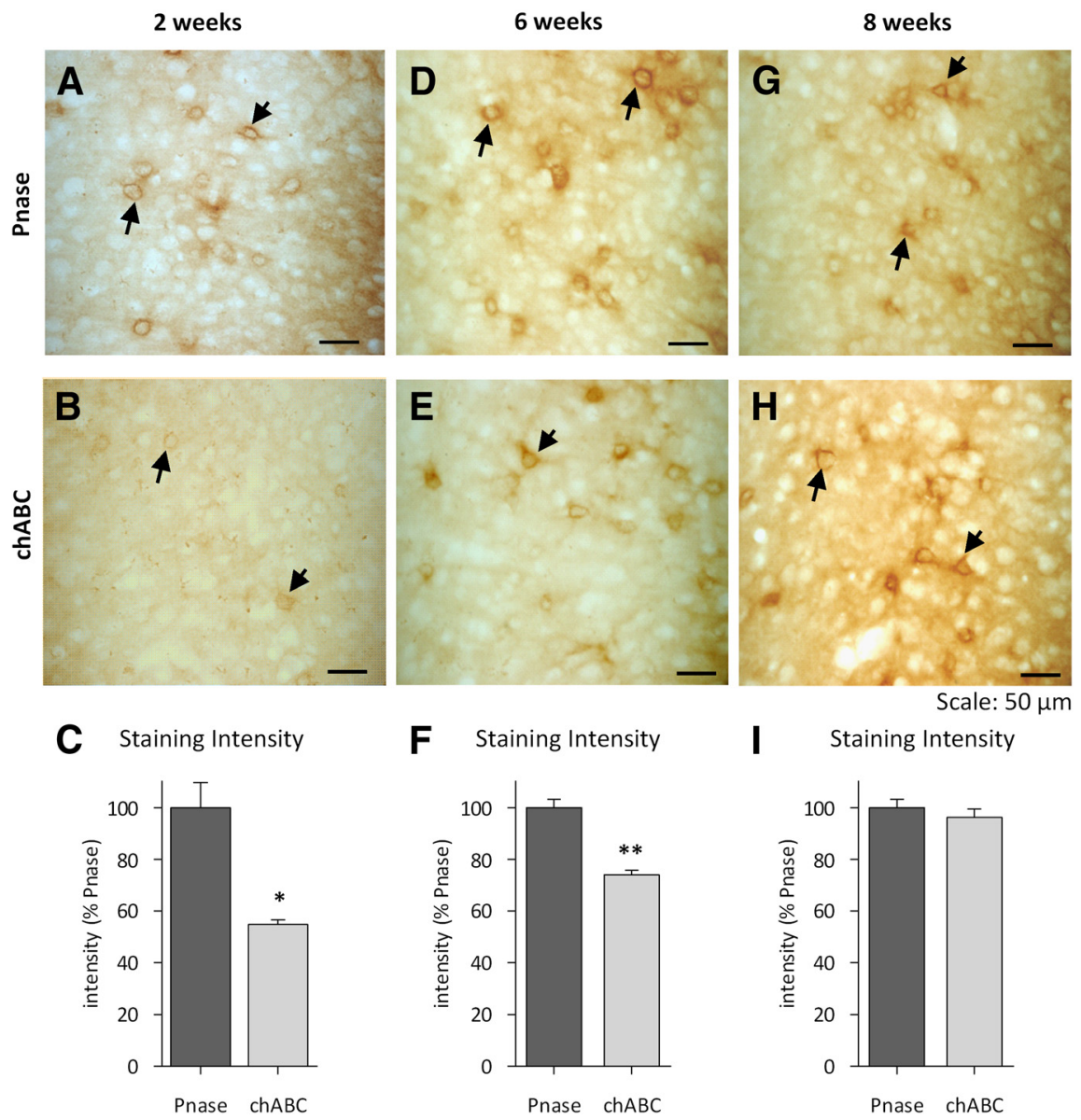

I

Staining Intensity

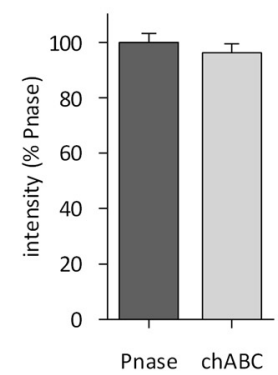

Figure 4. PNNs gradually repair after chABC treatment. W. floribunda agglutinin labeling of coronal sections at different time points after Pnase/chABC injections demonstrates the gradual restoration of PNNs over the course of 8 weeks. Two weeks after enzyme treatment, PNNs were still visible in Pnase-treated wt animals $(\boldsymbol{A})$, but were depleted in chABC-treated animals $(\boldsymbol{B})$. Staining intensity measures of the perirhinal cortex with ImageJ showed a profound reduction of labeling in chABC-treated mice ( $n=4$ per group; $t$ test, 2 weeks: $t=3.2 ; \boldsymbol{C}$. $\boldsymbol{D}, \boldsymbol{E}$, Six weeks after enzyme injections, PNNs started to reoccur in chABC-treated slices, but were still significantly reduced compared with Pnase-treated animals ( $n=4$ per group; $t$ test, $t=5.3 ; \boldsymbol{F}$ ). Eight weeks after enzyme injections, prominent PNNs were visible in Pnase- $(\boldsymbol{G})$ and chABC-treated animals $(\boldsymbol{H})$. Staining intensity measures of the perirhinal cortex indicated no significant difference of labeling between Pnase- and chABC-treated mice $(n=4$ per group; $t$ test, $t=0.8 ; I)$. Data are presented as mean \pm SEM. ${ }^{*} p<0.05 ;{ }^{* *} p<0.005$.

\section{A One week post chABC}

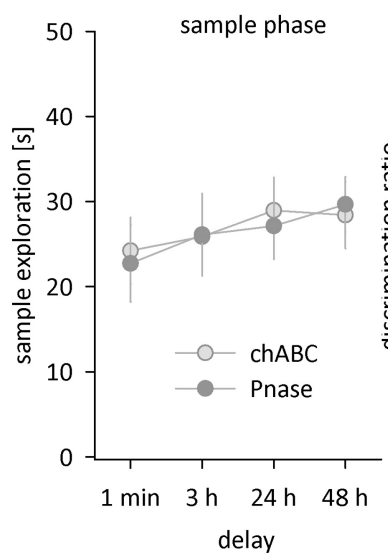

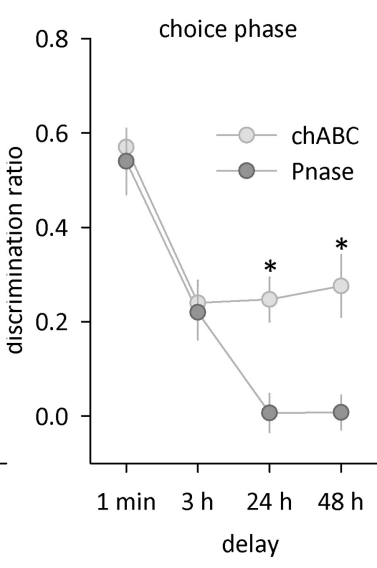

\section{B 3-8 weeks post chABC}

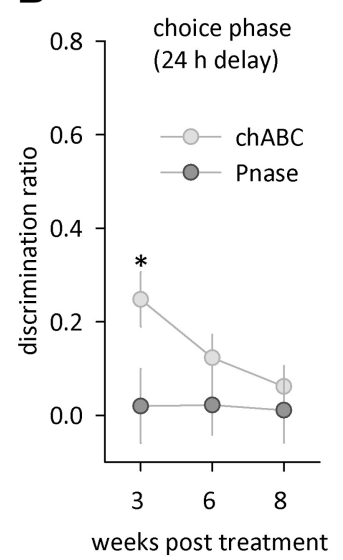

Figure 5. Enzymatic degradation of PNNs in the perirhinal cortex prolongs object recognition. $\boldsymbol{A}$, Sample exploration times of wt mice after chABC or Pnase treatment (left) and object preference on the choice phase after chABC or Pnase treatment (right, 1 min and 3 h delay: $\operatorname{ch} A B C n=7$, Pnase $n=8 ; 24$ and 48 h delay: $\operatorname{chABC} n=8$, Pnase $n=9) . B, 0$ bject recognition with a 24 h delay 3,6 , and 8 weeks after chABC or Pnase treatment (chABC: $n=5 ;$ Pnase: $n=5$ ). Data are presented as mean \pm SEM. ${ }^{*} p<0.05$, simple main effect. novelty-related behavior are minor and not the main reason for the effects observed.

If PNNs in the perirhinal cortex were causally related to the enhancement of object recognition memory, we hypothesized that it should be possible to convert the object recognition phenotype of wt mice into the phenotype of Crtll ko mice by acutely removing PNNs in the perirhinal cortex. To test this, we injected the CSPG-degrading enzyme chABC into the perirhinal cortex of the same Crtl1 ko and wt mice that had previously performed the object recognition task (cohort 1). This led to a long-term depletion of PNNs in the perirhinal cortex in the wt mice (Fig. 1C,D, Fig. 3, Fig. 4), but in addition to the $2 \%$ of CSPGs found in PNNs, chABC also digests the remainder found in the diffuse ECM (Deepa et al., 2006).

Seven days after chABC treatment, mice were retested on the same object recognition task with delays of 24 and $48 \mathrm{~h}$. Wt mice treated with chABC now showed the same memory prolongation as Crtl1 ko mice (Fig. $2 D$, Table 1). If the prolonged memory observed was due only to the digestion of CSPGs in PNNs, rather than the CSPGs in the diffuse ECM, digestion of the diffuse ECM in Crtll ko mice should have had no further effect on memory. In agreement with this hypothesis, chABC treatment did not affect object recognition in Crtl1 ko mice (Fig. 2D, Table 1), which adds to the evidence that PNNs regulate recognition memory.

To rule out that the enhancement of object recognition memory in chABCtreated wt mice was due to nonspecific effects of surgery and enzyme application, we repeated the above experiment with two new cohorts (cohort 2 and 3, see below) of wt mice that received either chABC or the control enzyme Pnase. Pnase treatment had no effect on PNNs, whereas chABC treatment significantly altered appearance and quantity of PNNs around perirhinal neurons (Fig. 3, Fig. $4 A-C)$. After a recovery period of 1 week, chABC/Pnase-treated mice were tested on the object recognition task with delays of 1 min or $3 \mathrm{~h}$ (cohort $2, n=7 / 8$ for chABC/ Pnase) or $24 \mathrm{~h}$ or $48 \mathrm{~h}$ (cohort $3, n=8 / 9$ for chABC/Pnase). On the choice phase, Pnase controls performed similarly to wt mice in the previous experiments, showing no memory of the familiar object by $24 \mathrm{~h}$ (Fig. $5 \mathrm{~A}$, right). In contrast, chABCtreated animals performed significantly better than Pnase-treated animals at longer delays and showed robust memory at 24 and 48 h (Fig. 5A, right, Table 2), sim- 
Table 2. RM ANOVA results chABC versus Pnase treatment

\begin{tabular}{|c|c|c|c|}
\hline Main effect or interaction & $F$ & $p$ & Simple main effects \\
\hline \multicolumn{4}{|c|}{$\begin{array}{l}\text { Discrimination ratio of chABC vs Pnase-treated wt mice: } \\
1 \mathrm{~min} \text { and } 3 \mathrm{~h} \text { delay }\end{array}$} \\
\hline Treatment & $F_{(1,13)}=0.002$ & $=0.967$ & \\
\hline Delay & $F_{(1,13)}=16.4$ & $=0.001$ & \\
\hline Treatment $\times$ delay & $F_{(1,13)}=0.8$ & $=0.776$ & \\
\hline \multicolumn{4}{|c|}{ Discrimination ratio of chABC vs Pnase-treated wt mice: 24 and $48 \mathrm{~h}$ delay } \\
\hline Treatment & $F_{(1,15)}=21.5$ & $<0.001$ & $\begin{array}{l}24 \mathrm{~h}: F_{(1,15)}=14.9, p=0.002 \\
48 \mathrm{~h}: F_{(1,15)}=13.3, p=0.002\end{array}$ \\
\hline Delay & $F_{(1,15)}=0.14$ & $=0.714$ & \\
\hline Treatment $\times$ delay & $F_{(1,15)}=0.12$ & $=0.738$ & \\
\hline \multicolumn{4}{|c|}{$\begin{array}{l}\text { Discrimination ratio of chABC vs Pnase-treated wt mice: } 3,6 \text {, and } 8 \text { weeks } \\
\text { posttreatment ( } 24 \mathrm{~h} \text { delay) }\end{array}$} \\
\hline Treatment & $F_{(1,8)}=3.5$ & $=0.097$ & \\
\hline Time & $F_{(1,8)}=7.5$ & $=0.026$ & \\
\hline Treatment $\times$ time & $F_{(1,8)}^{(1,0)}=6.1$ & $=0.038$ & $\begin{array}{l}3 \text { weeks: } F_{(1,8)}=6.7, p=0.033 \\
6 \text { weeks: } F_{(1,8)}=1.6, p=0.246 \\
8 \text { weeks: } F_{(1,8)}=0.4, p=0.555\end{array}$ \\
\hline
\end{tabular}

ilar to chABC-treated wt mice and Crtl1 ko mice in the previous experiments. These results, in particular the lack of an effect in Pnase-treated animals, further supports the conclusion that the memory enhancement seen in the first cohort after chABC treatment was due to its digestion of CSPGs. Overall, depletion of brain Crtll and chABC treatment to the perirhinal cortex both enhanced recognition memory to the same extent, supporting the hypothesis that enhanced recognition memory is related to the lack of PNNs. Sample exploration times during the sample phase were similar in all groups (Fig. $5 A$, left, RM ANOVAs, no main effects or interactions, all $F<1$ ).

Histology revealed that chABC-induced PNN degradation gradually recovered over the course of 2 months (Fig. 4). Therefore, we hypothesized that the memory of chABC-treated animals should eventually return to control levels. To test this, we repeatedly tested $24 \mathrm{~h}$ object recognition performance of the same animals (cohort 4, $n=5$ for each treatment) 3,6 , and 8 weeks after chABC or Pnase treatment. As predicted, the memory-enhancing effect of chABC gradually decreased with time (Fig. $5 B$ ). Consistent with the gradual reappearance of PNNs (Fig. 4), chABC-treated mice performed similarly to Pnase-treated animals 6 and 8 weeks after treatment (Fig. 5B, Table 2).

Object recognition memory is associated with long-term reductions in neuronal responsiveness in perirhinal cortex (Brown et al., 1987; Zhu et al., 1996; Xiang and Brown, 1998) and requires the expression of perirhinal LTD (Griffiths et al., 2008). To gain insights into the physiological mechanisms responsible for enhanced object recognition in Crtll ko mice, we measured perirhinal synaptic transmission, paired-pulse facilitation, and LTD in coronal slices from 4-month-old Crtl1 ko and wt mice

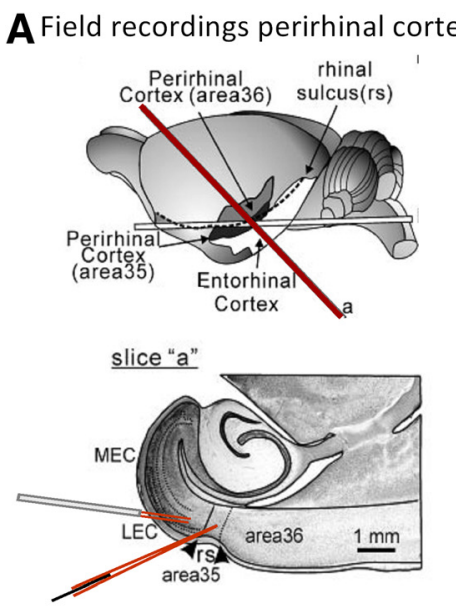

B Basal synaptic transmission

C Paired-pulse facilitation
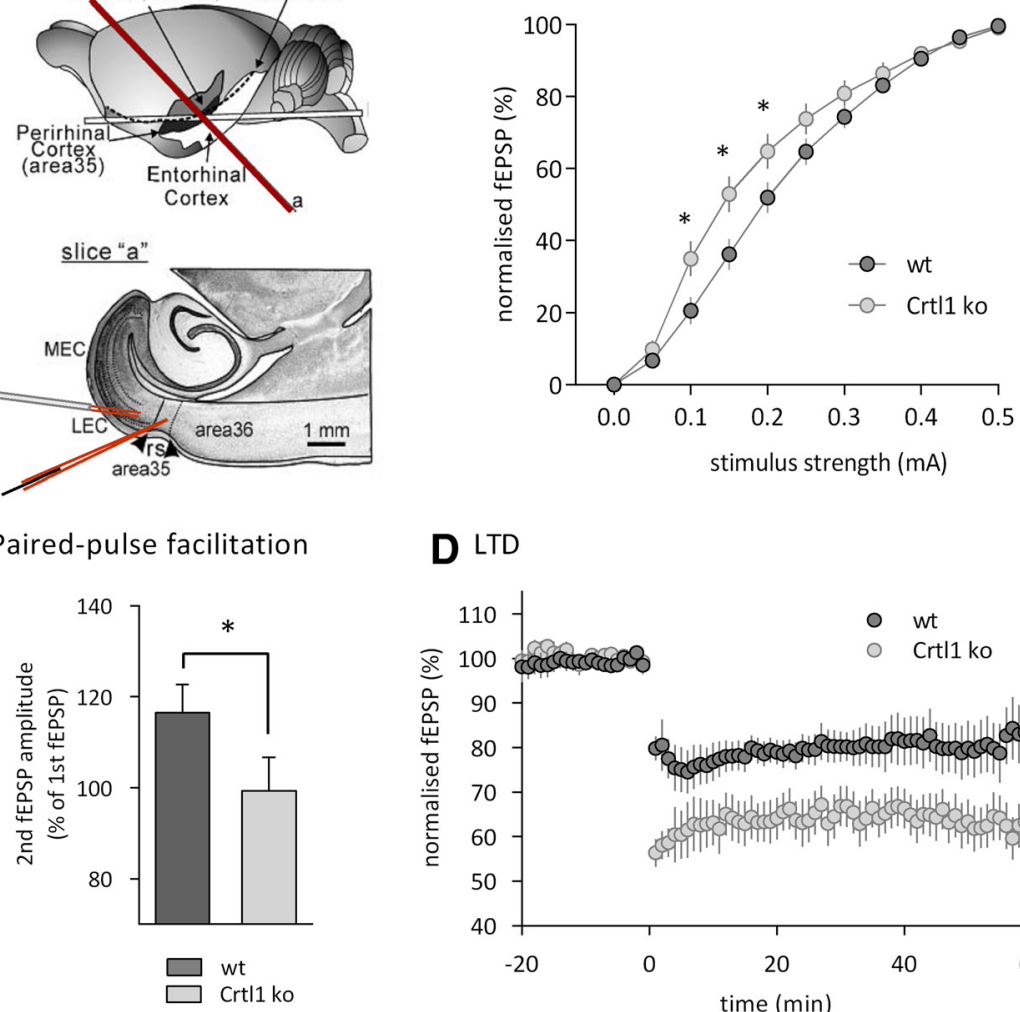

D LTD

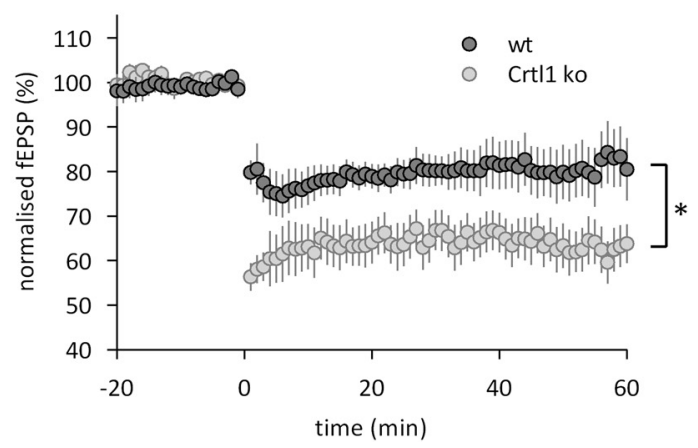

Figure 6. Altered synaptic transmission and plasticity in the perirhinal cortex of ( $\mathrm{rtt} 1 \mathrm{k}$ ko mice. $\boldsymbol{A}$, Setup for extracellular field recordings from perirhinal cortex in brain slices. $\boldsymbol{B}$, Layer II/III fEPSP amplitudes (normalized to the maximal amplitude) after stimulation of temporal layer II/III input with different stimulus intensities ( $n=9$ for both genotypes). C, Paired-pulse facilitation (wt: $n=10$; (rtl1 ko: $n=6$ ). D, LTD induced by low-frequency stimulation ( $n=6$ for both genotypes). Data are presented as mean \pm SEM. ${ }^{*} p<0.05$, simple main effects.

(Fig. 6A, cohort 5). Stimulation of temporal cortex input into layer II/III of the perirhinal cortex with different stimulus intensities revealed that basal fEPSPs in Crtl1 ko mice were greater than in wt mice (Fig. 6B, RM ANOVA, intensity $\times$ genotype interaction, $F_{(9,171)}=4.0, p<0.001$; trend of main effect of genotype: $\left.F_{(9,171)}=3.9, p=0.065\right)$. Furthermore, Crtl1 ko mice, in contrast to wt mice, showed no paired-pulse facilitation (Fig. 
6C, RM ANOVA, main effect of genotype, $F_{(1,14)}=14.7, p<$ 0.005; no further effects or interactions, all $F<1$ ). Moreover, LTD induction was greatly facilitated in Crtl1 ko mice, which expressed significantly smaller fEPSPs than wt mice 50 min after low-frequency stimulation (Fig. $6 D$, wt $81+/-4 \%$; Crtl1 ko 63 $+/-6 \%$; one-way ANOVA, main effect of genotype, $F_{(1,9)}=6.6$, $p<0.05)$.

Similar results were found in wt mice treated with chABC (cohort 6). Injections of chABC into the perirhinal cortex increased basal synaptic transmission (Fig. 7A, RM ANOVA, intensity $\times$ chABC interaction, $\left.F_{(9,216)}=2.1, p<0.05\right)$, reduced paired-pulse facilitation (Fig. $7 B, t$ test, $t_{32}=2.3, p<0.05$ ) and led to a significant increase of LTD at layer II/III synapses (Fig. $7 C$, 50 min after LFS: control $82.4 \pm 0.4 \%$; chABC $67 \pm 0.4 \%$; one-way ANOVA, main effect of chABC, $F_{(1,12)}=28.8, p<$ $0.001)$. The similarity of results obtained after genetic or pharmacological reduction of PNNs provides converging evidence that the removal of PNNs facilitates the induction of perirhinal LTD and increases synaptic transmission, providing a potential physiological correlate to superior object recognition in Crtl1 ko and chABC-treated animals.

\section{Discussion}

Attenuation of PNNs in the visual system has been shown to reopen the critical window for visual system plasticity (Pizzorusso et al., 2002; Carulli et al., 2010). Here, we demonstrate that PNNs also regulate recognition memory in adulthood: attenuation of PNNs either globally by genetic deletion of the Crtl1 gene or by localized application of chABC in the perirhinal cortex produced a profound enhancement of object recognition memory. Moreover, depletion of PNNs led to enhanced perirhinal LTD, thought to be the major synaptic mechanism underlying object recognition memory. The chABC-induced enhancement of object recognition was reversible: over the course of 8 weeks, memory gradually returned to control levels, suggesting that reoccurring PNNs gradually restore control plasticity levels.

Although previous evidence suggested that more general perturbations of the ECM can affect learning and memory, these earlier studies led to inconsistent results regarding the nature of the effect. For example, Morellini et al. (2010) reported that mice with deletion of the ECM protein tenascin-R showed normal hippocampus-dependent spatial memory, but were superior on subsequent reversal learning and working memory paradigms. In contrast, deletion of the ECM protein tenascin-C produced a deficit in hippocampus-dependent contextual memory (Strekalova et al., 2002). Gogolla et al. (2009) reported that chABC infused into the amygdala before fear conditioning had no effect on fear learning, but affected subsequent extinction, reinstatement, and renewal. Explanations for these diverse effects and controversies may partly be found in the different aspects of memory studied; furthermore, the range of treatments and genetic manipulations used affect not only PNNs, but also the composition of the ECM surrounding many types of neurons and glia. In our study, we therefore used a combined approach to address the function specifically of PNNs: the same improvement of memory was found after chABC treatment, which is regionally and temporally controlled but also has profound effects on other ECM structures, including digestion of the $98 \%$ of CSPGs not contained in PNNs, and after Crtll ko, which attenuates PNNs but does not alter the overall levels of CSPGs or their pattern of sulfation (Deepa et al., 2006; Carulli et al., 2010). Together with recent evidence that Crtl1 expression is the key molecular event triggering PNN formation (Carulli et al., 2010; Kwok et al., 2010), the similarity of our results from both

\section{A Basal synaptic transmission after chABC treatment}

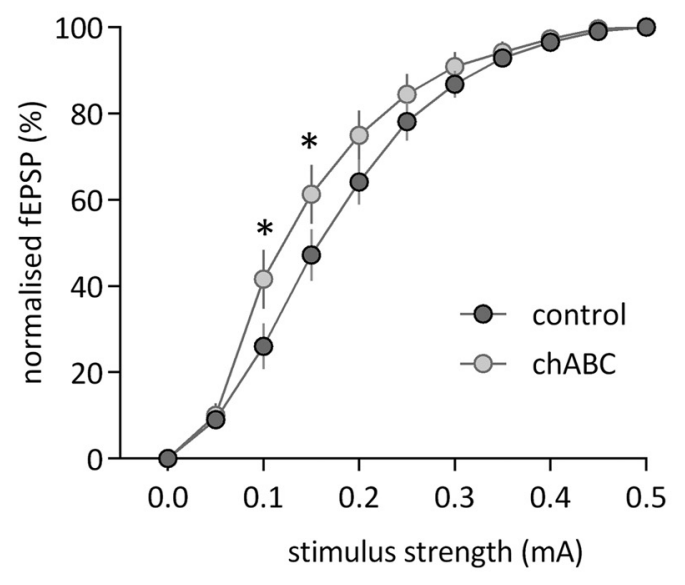

B Paired-pulse facilitation after chABC treatment

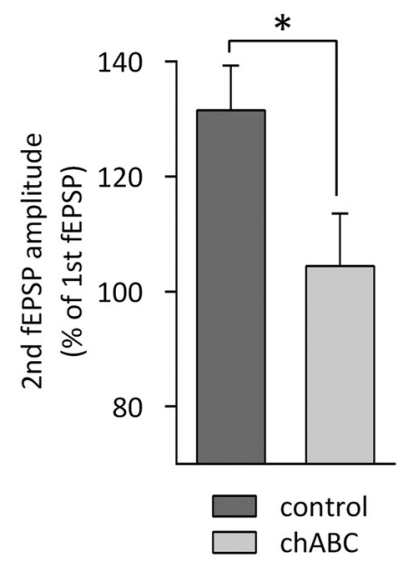

C LTD after chABC treatment

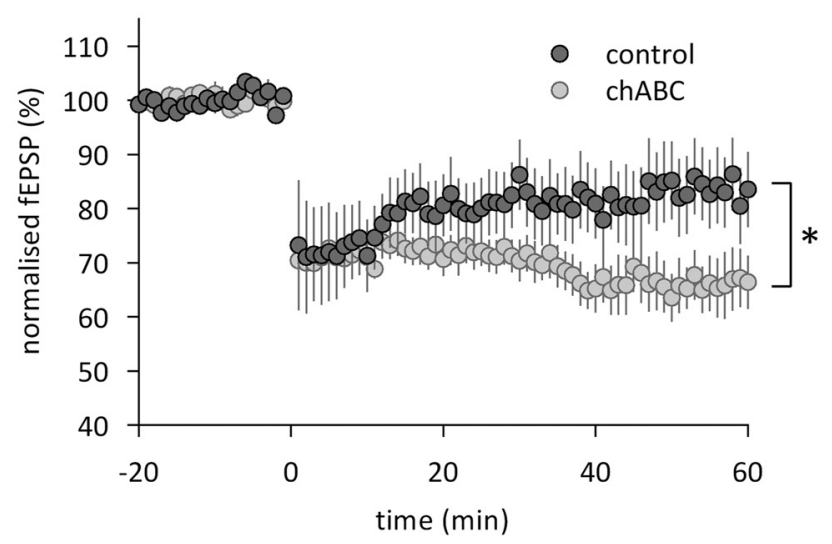

Figure 7. Altered synaptic transmission and plasticity in the perirhinal cortex of chABCtreated mice. $A$, Layer II/III fEPSP amplitudes (normalized to the maximal amplitude) after stimulation of temporal layer II/III input with different stimulus intensities ( $n=14$ for Pnasetreated mice (control); $n=12$ for chABC-treated mice). $\boldsymbol{B}$, Paired-pulse facilitation (control: $n=19$; chABC: $n=15$ ). C, LTD induced by low-frequency stimulation (control: $n=7$; chABC: $n=6)$. Data are presented as mean \pm SEM. ${ }^{*} p<0.05$, simple main effects.

approaches gives us confidence that the clear improvement of recognition memory is related to compromised PNNs, rather than being a consequence of general alterations to the ECM.

The principal physiological mechanisms thought to support object recognition memory are LTD-like processes in the perirhinal cortex (Zhu et al., 1996; Xiang and Brown, 1998; Warburton 
et al., 2003; Wan et al., 2004; Warburton et al., 2005; Barker et al., 2006; Griffiths et al., 2008; Massey et al., 2008; Kealy and Commins, 2011). We found that the Crtl1 ko mice and chABCtreated animals showed a facilitation of perirhinal LTD, which may be sufficient to explain superior familiarity detection. We also observed reduced paired-pulse facilitation and an increase in basal synaptic transmission. The pattern of results suggests that the depletion of brain Crtl1/PNNs may alter the induction or expression rules for synaptic plasticity: high basal synaptic transmission levels or other mechanisms facilitate LTD, but reduce the potential for paired-pulse facilitation.

How PNNs alter synaptic plasticity in the perirhinal cortex is unclear. Given the pattern of enhanced excitatory synaptic transmission and facilitated LTD in the perirhinal cortex of Crtl1/ chABC-treated mice, PNNs might in some way regulate the influence of GABA-mediated inhibition (but see Frischknecht et al., 2009 for direct actions of PNNs on AMPA receptor mobility). This hypothesis seems particularly intriguing, because an increase in intracortical inhibition mediated by parvalbumincontaining neurons contributes to the closure of the critical period in the visual cortex (Huang et al., 1999; Berardi et al., 2000; Hensch, 2004), and PNNs are mostly, but not exclusively, located around such perisomatic GABAergic interneurons (Celio, 1993; Alpár et al., 2006). Not mutually exclusive of alterations in GABAergic transmission, depletion of PNNs may also shift the relative contributions of multiple coexisting LTD induction mechanisms (Cho et al., 2000; Cho and Bashir, 2002; Harris et al., 2004; Park et al., 2006). In particular, the lack of PNNs may have preserved/reinstated juvenile LTD induction mechanisms characteristic for early postnatal development (Jo et al., 2006).

Overall, our data suggest that the removal of PNNs not only promotes plasticity and regeneration of sensory/motor systems (Bradbury et al., 2002; Carulli et al., 2010), but also facilitates cognitive abilities in adults by altering the rules of underlying, experience-driven synaptic plasticity. Our findings in mice do not have direct clinical implications, but altering the sensitivity to synaptic plasticity by manipulation of PNNs may provide a clinically relevant opportunity for the symptomatic enhancement of recognition memory in aging, as well as in Alzheimer's disease and other disorders of cognition. Although the focus of the current study was on the effect of PNNs on experience-driven learning, our findings might also be informative on how ECM modification enhances recovery after lesions. Previous studies in which chABC has enhanced recovery from spinal cord injury and other conditions have focused on the increase in sprouting of corticospinal and other axons in treated animals and suggested that the formation of new connections through sprouting is the main mechanism of recovery. Our current results suggest that changes in synaptic function could be equally important and may also be relevant to the ability of chABC treatment to enhance the effectiveness of rehabilitation (García-Alías et al., 2009; Bartus et al., 2012; Sharma et al., 2012).

\section{References}

Alpár A, Gärtner U, Härtig W, Brückner G (2006) Distribution of pyramidal cells associated with perineuronal nets in the neocortex of rat. Brain Res 1120:13-22. CrossRef Medline

Barker GR, Warburton EC, Koder T, Dolman NP, More JC, Aggleton JP, Bashir ZI, Auberson YP, Jane DE, Brown MW (2006) The different effects on recognition memory of perirhinal kainate and NMDA glutamate receptor antagonism: implications for underlying plasticity mechanisms. J Neurosci 26:3561-3566. CrossRef Medline

Bartko SJ, Romberg C, White B, Wess J, Bussey TJ, Saksida LM (2011) Intact attentional processing but abnormal responding in $\mathrm{M}(1)$ muscarinic receptor-deficient mice using an automated touchscreen method. Neuropharmacology 61:1366-1378. CrossRef Medline

Bartus K, James ND, Bosch KD, Bradbury EJ (2012) Chondroitin sulphate proteoglycans: key modulators of spinal cord and brain plasticity. Exp Neurol 235:5-17. CrossRef Medline

Berardi N, Pizzorusso T, Maffei L (2000) Critical periods during sensory development. Curr Opin Neurobiol 10:138-145. CrossRef Medline

Bliss TV, Collingridge GL (1993) A synaptic model of memory: long-term potentiation in the hippocampus. Nature 361:31-39. CrossRef Medline

Bradbury EJ, Moon LD, Popat RJ, King VR, Bennett GS, Patel PN, Fawcett JW, McMahon SB (2002) Chondroitinase ABC promotes functional recovery after spinal cord injury. Nature 416:636-640. CrossRef Medline

Brown MW, Wilson FA, Riches IP (1987) Neuronal evidence that inferomedial temporal cortex is more important than hippocampus in certain processes underlying recognition memory. Brain Res 409:158-162. CrossRef Medline

Bussey TJ, Saksida LM (2007) Memory, perception, and the ventral visualperirhinal-hippocampal stream: thinking outside of the boxes. Hippocampus 17:898-908. CrossRef Medline

Carulli D, Rhodes KE, Fawcett JW (2007) Upregulation of aggrecan, link protein 1, and hyaluronan synthases during formation of perineuronal nets in the rat cerebellum. J Comp Neurol 501:83-94. CrossRef Medline

Carulli D, Pizzorusso T, Kwok JC, Putignano E, Poli A, Forostyak S, Andrews MR, Deepa SS, Glant TT, Fawcett JW (2010) Animals lacking link protein have attenuated perineuronal nets and persistent plasticity. Brain 133:2331-2347. CrossRef Medline

Celio MR (1993) Perineuronal nets of extracellular matrix around parvalbumin-containing neurons of the hippocampus. Hippocampus. 1993;3 Spec No:55-60. Medline

Cho K, Bashir ZI (2002) Cooperation between mglu receptors: a depressing mechanism? Trends Neurosci 25:405-411. CrossRef Medline

Cho K, Kemp N, Noel J, Aggleton JP, Brown MW, Bashir ZI (2000) A new form of long-term depression in the perirhinal cortex. Nat Neurosci 3:150-156. CrossRef Medline

Czipri M, Otto JM, Cs-Szabó G, Kamath RV, Vermes C, Firneisz G, Kolman KJ, Watanabe H, Li Y, Roughley PJ, Yamada Y, Olsen BR, Glant TT (2003) Genetic rescue of chondrodysplasia and the perinatal lethal effect of cartilage link protein deficiency. J Biol Chem 278:39214-39223. CrossRef Medline

Deepa SS, Carulli D, Galtrey C, Rhodes K, Fukuda J, Mikami T, Sugahara K, Fawcett JW (2006) Composition of perineuronal net extracellular matrix in rat brain: a different disaccharide composition for the netassociated proteoglycans. J Biol Chem 281:17789-17800. CrossRef Medline

Dityatev A, Schachner M, Sonderegger P (2010) The dual role of the extracellular matrix in synaptic plasticity and homeostasis. Nat Rev Neurosci 11:735-746. CrossRef Medline

Eichenbaum H, Yonelinas AP, Ranganath C (2007) The medial temporal lobe and recognition memory. Annu Rev Neurosci 30:123-152. CrossRef Medline

Ennaceur A, Delacour J (1988) A new one-trial test for neurobiological studies of memory in rats. 1: Behavioral data. Behav Brain Res 31:47-59. CrossRef Medline

Ennaceur A, Neave N, Aggleton JP (1996) Neurotoxic lesions of the perirhinal cortex do not mimic the behavioural effects of fornix transection in the rat. Behav Brain Res 80:9-25. CrossRef Medline

Forwood SE, Winters BD, Bussey TJ (2005) Hippocampal lesions that abolish spatial maze performance spare object recognition memory at delays of up to 48 hours. Hippocampus 15:347-355. CrossRef Medline

Frischknecht R, Heine M, Perrais D, Seidenbecher CI, Choquet D, Gundelfinger ED (2009) Brain extracellular matrix affects AMPA receptor lateral mobility and short-term synaptic plasticity. Nat Neurosci 12:897-904. CrossRef Medline

Gaffan D (1974) Recognition impaired and association intact in the memory of monkeys after transection of the fornix. J Comp Physiol Psychol 86:1100-1109. CrossRef Medline

García-Alías G, Barkhuysen S, Buckle M, Fawcett JW (2009) Chondroitinase $\mathrm{ABC}$ treatment opens a window of opportunity for task-specific rehabilitation. Nat Neurosci 12:1145-1151. CrossRef Medline

Gogolla N, Caroni P, Lüthi A, Herry C (2009) Perineuronal nets protect fear memories from erasure. Science 325:1258-1261. CrossRef Medline

Griffiths S, Scott H, Glover C, Bienemann A, Ghorbel MT, Uney J, Brown 
MW, Warburton EC, Bashir ZI (2008) Expression of long-term depression underlies visual recognition memory. Neuron 58:186-194. CrossRef Medline

Harris SL, Cho K, Bashir ZI, Molnar E (2004) Metabotropic glutamate receptor signalling in perirhinal cortical neurons. Mol Cell Neurosci 25: 275-287. CrossRef Medline

Härtig W, Brauer K, Brückner G (1992) Wisteria floribunda agglutininlabelled nets surround parvalbumin-containing neurons. Neuroreport 3:869-872. CrossRef Medline

Hensch TK (2004) Critical period regulation. Annu Rev Neurosci 27:549579. CrossRef Medline

Huang ZJ, Kirkwood A, Pizzorusso T, Porciatti V, Morales B, Bear MF, Maffei L, Tonegawa S (1999) BDNF regulates the maturation of inhibition and the critical period of plasticity in mouse visual cortex. Cell 98:739-755. CrossRef Medline

Jo J, Ball SM, Seok H, Oh SB, Massey PV, Molnar E, Bashir ZI, Cho K (2006) Experience-dependent modification of mechanisms of long-term depression. Nat Neurosci 9:170-172. CrossRef Medline

Kealy J, Commins S (2011) The rat perirhinal cortex: A review of anatomy, physiology, plasticity, and function. Prog Neurobiol 93:522-548. CrossRef Medline

Kwok JC, Carulli D, Fawcett JW (2010) In vitro modeling of perineuronal nets: hyaluronan synthase and link protein are necessary for their formation and integrity. J Neurochem 114:1447-1459. CrossRef Medline

Kwok JC, Dick G, Wang D, Fawcett JW (2011) Extracellular matrix and perineuronal nets in CNS repair. Dev Neurobiol 71:1073-1089. CrossRef Medline

Manns JR, Squire LR (1999) Impaired recognition memory on the Doors and People Test after damage limited to the hippocampal region. Hippocampus 9:495-499. CrossRef Medline

Martin SJ, Morris RG (2002) New life in an old idea: the synaptic plasticity and memory hypothesis revisited. Hippocampus 12:609-636. CrossRef Medline

Massey PV, Phythian D, Narduzzo K, Warburton EC, Brown MW, Bashir ZI (2008) Learning-specific changes in long-term depression in adult perirhinal cortex. J Neurosci 28:7548-7554. CrossRef Medline

Mishkin M (1978) Memory in monkeys severely impaired by combined but not by separate removal of amygdala and hippocampus. Nature 273:297-298. CrossRef Medline

Morellini F, Sivukhina E, Stoenica L, Oulianova E, Bukalo O, Jakovcevski I, Dityatev A, Irintchev A, Schachner M (2010) Improved reversal learning and working memory and enhanced reactivity to novelty in mice with enhanced GABAergic innervation in the dentate gyrus. Cereb Cortex 20: 2712-2727. CrossRef Medline

Mörgelin M, Heinegård D, Engel J, Paulsson M (1994) The cartilage proteoglycan aggregate: assembly through combined protein-carbohydrate and protein-protein interactions. Biophys Chem 50:113-128. CrossRef Medline

Murray EA, Bussey TJ (1999) Perceptual-mnemonic functions of the perirhinal cortex. Trends Cogn Sci 3:142-151. CrossRef Medline
Park Y, Jo J, Isaac JT, Cho K (2006) Long-term depression of kainate receptor-mediated synaptic transmission. Neuron 49:95-106. CrossRef Medline

Pizzorusso T, Medini P, Berardi N, Chierzi S, Fawcett JW, Maffei L (2002) Reactivation of ocular dominance plasticity in the adult visual cortex. Science 298:1248-1251. CrossRef Medline

Saksida LM (2009) Neuroscience. Remembering outside the box. Science 325:40-41. CrossRef Medline

Sharma H, Alilain WJ, Sadhu A, Silver J (2012) Treatments to restore respiratory function after spinal cord injury and their implications for regeneration, plasticity and adaptation. Exp Neurol 235:18-25. CrossRef Medline

Squire LR, Zola-Morgan S (1988) Memory: brain systems and behavior. Trends Neurosci 11:170-175. CrossRef Medline

Strekalova T, Sun M, Sibbe M, Evers M, Dityatev A, Gass P, Schachner M (2002) Fibronectin domains of extracellular matrix molecule tenascin-C modulate hippocampal learning and synaptic plasticity. Mol Cell Neurosci 21:173-187. CrossRef Medline

Wan H, Warburton EC, Zhu XO, Koder TJ, Park Y, Aggleton JP, Cho K, Bashir ZI, Brown MW (2004) Benzodiazepine impairment of perirhinal cortical plasticity and recognition memory. Eur J Neurosci 20:2214-2224. CrossRef Medline

Warburton EC, Koder T, Cho K, Massey PV, Duguid G, Barker GR, Aggleton JP, Bashir ZI, Brown MW (2003) Cholinergic neurotransmission is essential for perirhinal cortical plasticity and recognition memory. Neuron 38:987-996. CrossRef Medline

Warburton EC, Glover CP, Massey PV, Wan H, Johnson B, Bienemann A, Deuschle U, Kew JN, Aggleton JP, Bashir ZI, Uney J, Brown MW (2005) cAMP responsive element-binding protein phosphorylation is necessary for perirhinal long-term potentiation and recognition memory. J Neurosci 25:6296-6303. CrossRef Medline

Watanabe H, Yamada Y, Kimata K (1998) Roles of aggrecan, a large chondroitin sulfate proteoglycan, in cartilage structure and function. J Biochem 124:687-693. CrossRef Medline

Winters BD, Forwood SE, Cowell RA, Saksida LM, Bussey TJ (2004) Double dissociation between the effects of peri-postrhinal cortex and hippocampal lesions on tests of object recognition and spatial memory: heterogeneity of function within the temporal lobe. J Neurosci 24:5901-5908. CrossRef Medline

Winters BD, Saksida LM, Bussey TJ (2008) Object recognition memory: neurobiological mechanisms of encoding, consolidation and retrieval. Neurosci Biobehav Rev 32:1055-1070. CrossRef Medline

Xiang JZ, Brown MW (1998) Differential neuronal encoding of novelty, familiarity and recency in regions of the anterior temporal lobe. Neuropharmacology 37:657-676. CrossRef Medline

Zhu XO, McCabe BJ, Aggleton JP, Brown MW (1996) Mapping visual recognition memory through expression of the immediate early gene c-fos. Neuroreport 7:1871-1875. CrossRef Medline 